\title{
A crise económica e as boas práticas clínicas
}

Raquel Braga*

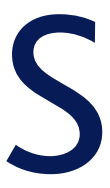

e formos capazes, olhemos para o que a crise económica nos traz como se olhássemos para o copo que está meio cheio...

A crise económica pode ser uma oportunidade de nos debruçarmos e desenvolvermos reflexões acerca das boas práticas clínicas. Pode ser mesmo uma preciosa motivação para reflectirmos acerca de prevenção quaternária, ou seja dos danos, mais que dos benefícios, que podemos causar pelos excessos da iatrogenia. ${ }^{1,2,3}$

Certamente, todos concordamos que na nossa prática clínica há desperdícios, quer na orientação diagnóstica, quer na prescrição terapêutica.

Mesmo os médicos mais comedidos e racionais já alguma vez se interrogaram, revendo certos processos clínicos - «Porque é que eu solicitei esta análise ou este exame complementar?...»

Racionalizar a actividade clínica pode, sem dúvida, conduzir à diminuição de desperdícios.

Esse esforço, contudo, só pode substanciar-se através da formação médica e pela aposta numa cultura de boas práticas clínicas.

Claro que esta cultura não deveria nascer da crise económica, mas sim da sofisticação científica.

Não obstante, centremo-nos no que a crise nos pode trazer de bom, já que naturalmente sentimos na pele o que nos traz de negativo...

A elaboração de Normas de Orientação Clínica (NOC), para começar, pode ser um excelente motor de reflexão acerca de erros e um precioso auxílio para guiarmos a nossa conduta, mas sobretudo para fundamentarmos os nossos procedimentos.

Muitas vezes, a avaliação do custo-benefício está na origem da elaboração de NOC, sendo que os custos económicos nem sempre são os únicos que podem ou devem ser tidos em conta.

*Directora da Revista Portuguesa de Clínica Geral
Desde que sejam orientadoras e não limitadoras ou restritivas do bom senso clínico, desde que baseadas nas melhores provas científicas e bem adequadas à nossa população e contexto local, as NOC são ferramentas importantes, e há muito tardavam em Portugal.

No entanto, a profusão e a celeridade com que estão a ser produzidas, nos últimos tempos, na nossa área, fruto de pressões económicas, podem condicionar menor cuidado e ponderação na sua elaboração e revisão pelas entidades de direito, a Ordem dos Médicos (na figura do Colégio de Medicina Geral e Familiar) e a Associação Portuguesa de Médicos de Clínica Geral, na condição de sociedade científica. O tempo dirá se o rigor na sua elaboração e revisão foi suficiente e adequado.

Pensemos nestas normas como mais um passo na criação de uma cultura de boas práticas.

O que não convém é ficar desatento e deixar que cristalizem, sem que haja uma melhoria contínua ou falta de rigor e profissionalismo na manutenção da sua produção e actualização.

Outro factor económico relevante a ter em conta em tempos de crise é a prescrição de genéricos, como forma de reduzir custos.

A Ordem dos Médicos é defensora e recomenda «a prescrição dos medicamentos que, em cada momento, apresentem a melhor relação custo/benefício para o Doente, seja objecto da confiança e experiência do Médico e resulte do diálogo possível com o Doente.» ${ }^{4}$ Neste contexto, a Ordem do Médicos é favorável à prescrição de medicamentos genéricos. Esta posição, subscrita por boa parte dos médicos, é a da existência de confiança nos genéricos mas não na política do medicamento (que facilita as trocas de genéricos nas farmácias, potenciando a confusão dos genéricos pelos utentes; que possibilta a aprovação ilimitada de genéricos; que facilita fixação de preços discutíveis, etc).

Apesar do percurso pouco consensual que esteve na 
base da sua introdução, muito já foi feito na área dos medicamentos genéricos em Portugal. Ainda assim, a nossa percentagem de prescrição de genéricos ronda os $30 \%$. Países mais ricos que o nosso têm quotas superiores.

Esta poderá ser uma área a melhorar.

A questão dos genéricos não esgota, no entanto, o tema da racionalização da prescrição.

Uma prescrição racional envolve outros factores que os médicos deveriam dominar e ponderar. Haverá uma cultura e ensino médico dirigido às boas práticas nesta área ou somos, como se supõe, demasiado vulneráveis a apelos menos racionais ${ }^{5}$

Os principais factores que devem nortear uma correcta prescrição podem resumir-se no acrónimoSTEPS (Segurança, Tolerabilidade, Efectividade, Preço, Simplicidade). ${ }^{6}$

Não devemos ignorar que mais de $10 \%$ dos novos fármacos comercializados nos últimos 25 anos foram considerados medicamentos sob vigilância (black box warning) ou retirados do mercado. Por este motivo, não devemos prescrever novos fármacos até que eles demonstrem ser mais seguros ou efectivos na melhoria de resultados que interessam aos doentes do que os fármacos já existentes. ${ }^{7}$

Não esgotando talvez este tema, factores de grande impacto são também as alterações relativas à política do medicamento, às taxas moderadoras de consultas, internamentos e exames.

Fruto do aumento dos preços, cidadãos e profissionais de saúde começam generalizadamente a perceber e a respeitar o valor do medicamento, o preço de uma consulta, ou de um exame complementar.

De repente, todos damos apreço ao que de tão bom e acessível tivemos e estamos em vias de perder...

Portugal, tendo um Serviço Nacional de Saúde que foi considerado o seu melhor serviço público, capaz de nos colocar na liderança mundial em termos de indicadores de saúde e de os incrementar a uma velocidade espantosa e constante, capaz de trazer equidade e qualidade nos cuidados prestados, não pode descurar o que alcançou.
Ouve-se dizer: «Nunca pensei que isto fosse tão caro!»

Inevitavelmente, o que é caro tem valor, torna-se imperioso poupá-lo para quando é realmente necessário e todos parecem compreender e aceitar este facto melhor do que em tempos de maior abundância.

Supondo que o impacto de diminuir ligeiramente a quantidade de serviços prestados, desde que a qualidade seja mantida, não é muito grande, já tornar ainda mais difícil o acesso aos cuidados de saúde dos que são realmente desfavorecidos é realmente grave. Acentuar a lei da inversão dos cuidados de saúde é um perigo real, que devemos combater a todo o custo.,

Com a crise económica torna-se mais criteriosa a utilização dos recursos de saúde. Dá-se o real valor àquilo que sabemos que não tem preço. Todos somos mais compreensivos e sensíveis a combater os desperdícios.

E se isto não fosse mau... até poderia ser bom.

\section{REFERÊNCIAS BIBLIOGRÁFICAS}

1. Jamoulle M. Quaternary prevention: First, do not harm. 11th Congress of the Sociedade Brasileira de Medicina de Família e Comunidade (SBMFC), Brazilia, 2011 June 23-26.

2. Gervas J. La prevención cuaternária. OMC 2004 Jun; 95: 8.

3. Melo M. A prevenção quaternária contra os excessos da medicina. Rev Port Clin Geral 2007 Mai-Jun; 23 (3): 289-93.

4. Ordem apresentou no Parlamento posição sobre prescrição por DCl. Revista da Ordem dos Médicos 2011 Fev; 27 (116): 8-10.

5. Melo M, Braga R. As visitas dos Delegados de Informação Médica: qual a utilidade da sua informação? Rev Port Clin Geral 2003 Set-Out; 19 (5): 503-9.

6. Shaughnessy AF. STEPS drug updates. Am Fam Physician 2003 Dec 15; 68 (12): 2342-8.

7. Lasser KE, Allen PD, Woolhandler SJ, Himmelstein DU, Wolfe SM, Bor $\mathrm{DH}$. Timing of new black box warnings and withdrawals for prescription medications. JAMA 2002 May 1; 287 (17): 2215-20.

8. Hart JT. The inverse care law. Lancet 1971 Feb 27; 1 (7696): 405-12.

9. Ramos V. Regulação na saúde e a "lei da inversão dos cuidados de J.T. Hart". Disponível em: http://www.observaport.org/sites/observaport.org/files/regulacao-saude-lei-inversao-cuidados-jthart.pdf [acedido em 05/10/2011].

ENDEREÇO PARA CORRESPONDÊNCIA

director@rpcg.apmcg.pt 